\title{
Multiple Angulated Mammography Reconstructions in Digital Breast Tomosynthesis for the Diagnosis of Microcalcifications - Added Value to Standard Stack Reconstructions and Synthesized Mammography Mehrfach angulierte Mammografierekonstruktionen in digitaler Brust-Tomosynthese für die Diagnostik von Mikroverkalkungen - Vorteile im Vergleich zu Standard-Schicht-Rekonstruktionen und Synthetisierter Mammografie
}

Authors

Jakob Neubauer ${ }^{1}$, Claudia Neubauer $^{1}$, Julia Wicklein ${ }^{2}$, Thomas Mertelmeier ${ }^{2}$, Marisa Windfuhr-Blum ${ }^{1}$, Mathias Langer $^{1}$

Affiliation

1 Radiology, Medical Center - University of Freiburg, Faculty of Medicine, University of Freiburg, Germany, Freiburg, Germany

2 Diagnostic Imaging, Siemens Healthcare GmbH, Erlangen, Germany

Key words

synthezised mammography, insight3D, image manipulation/ reconstruction, breast, microcalcifications, digital breast tomosynthesis

received 12.06 .2017

accepted 17.12.2017

Bibliography

DOI https://doi.org/10.1055/s-0044-100726

Published online: 1.2.2018

Fortschr Röntgenstr 2018; 190: 433-440

(C) Georg Thieme Verlag KG, Stuttgart · New York ISSN 1438-9029

Correspondence

Herr Dr. Jakob Neubauer

Radiologie, Universitätsklinikum Freiburg, Hugstetterstr. 55,

79106 Freiburg, Germany

Tel.: ++ 49/761/270-3 8262

Fax: $++49 / 761 / 270-38300$

jakob.neubauer@uniklinik-freiburg.de

\section{ZUSAMMENFASSUNG}

Zweck Vergleich der Bildqualitätsbewertungen, diagnostischen Genauigkeit und Läsionscharakterisierung von synthetischer Mammografie (SM), mehrfach angulierten Mammografierekonstruktionen (INSIGHT3D) und StandardSchicht-Rekonstruktionen für Mikroverkalkungen in der digitalen Brust-Tomosynthese.

Materialen und Methoden Dies ist eine retrospektive Multicase-Multireader-Studie. Eingeschlossen wurden Patienten mit digitaler Brust-Tomosynthese (DBT), Mikroverkalkungen und Histologie über einen Zeitraum von vier Monaten in unserer Institution und die gleiche Anzahl von normalen Fällen. Drei verblindete Radiologen beurteilten unabhängig voneinander die Darstellung, Verteilung, Morphologie und den BI-RADS-Score von Mikroverkalkungen in SM, INSIGHT3D und Standard-Schicht-Rekonstruktionen. Die Bilder wurden anonymisiert und in zufälliger Reihenfolge präsentiert. Die Lesezeit wurde gemessen. Friedman und Post-hoc-NemenyiTests, Cochrane's Q und Post-hoc-Wilcoxon-VorzeichenRang-Tests, Fleiss'-Kappa- und Receiver Operating Characteristics wurden für die statistische Analyse verwendet.

Ergebnisse Wir haben 41 histopathologisch gesicherte und 41 normale Fälle eingeschlossen. Die Erkennbarkeit von Mikroverkalkungen wurde mit INSIGHT3D besser bewertet als mit SM und besser mit den Standard-Schicht-Rekonstruktionen als mit INSIGHT3D und SM $(P<0,001)$. Die Lesezeit war mit SM und INSIGHT3D im Vergleich zu Standard-Schicht-Rekonstruktionen niedriger $(P<0,001)$. Die diagnostische Genauigkeit und die Korrelation unter den Beobachtern waren vergleichbar zwischen allen getesteten Rekonstruktionen.

Schlussfolgerungen Im Vergleich zur SM zeigt INSIGHT3D bessere Bewertungen bezüglich der Erkennbarkeit von Mikroverkalkungen, wobei eine kurze Befundungszeit beibehalten wird. Diese erste Untersuchung legt einen Vorteil von INSIGHT3D gegenüber der SM nahe.

\section{Kernaussagen}

- INSIGHT3D stellt Mikroverkalkungen besser dar als die synthetische Mammografie unter Beibehaltung einer kurzen Befundungszeit.

- Die diagnostische Genauigkeit und Inter-Rater-Korrelation waren vergleichbar zwischen INSIGHT3D und synthetischer Mammografie.

- INSIGHT3D könnte die synthetische Mammografie möglicherweise ersetzen. 


\section{ABSTRACT}

Purpose To compare ratings regarding the depiction, diagnostic accuracy and lesion characterization of conventional synthesized mammography (SM), multiple angulated mammography reconstructions (INSIGHT3D), and standard stack reconstructions in digital breast tomosynthesis for microcalcifications.

Materials and Methods This is a retrospective, multicase, multireader study. We included patients with digital breast tomosynthesis (DBT), microcalcifications and histology over a period of four months in our institution and the same number of normal cases. Three radiologists, who were blinded to patient data, independently rated the depiction, distribution, morphology and BI-RADS score of microcalcifications in SM, INSIGHT3D and standard stack reconstructions. Deidentified images were presented in random order. Reading time was measured. Friedman and post hoc Nemenyi tests, Cochrane's $\mathrm{Q}$ and post hoc Wilcoxon signed rank tests, Fleiss' kappa and receiver operating characteristics were used for statistical analysis.

Results We included 41 histopathologically proven and 41 normal cases. Depiction of microcalcifications was rated better in INSIGHT3D than in SM and better in stack reconstructions than in INSIGHT3D and SM $(P<0.001)$. The reading time was lower in SM and INSIGHT3D compared to stack reconstructions $(\mathrm{P}<0.001)$. The diagnostic accuracy and inter-rater correlation were comparable between all tested modes of reconstruction.

Conclusions INSIGHT3D has higher ratings regarding the depiction of microcalcifications compared to SM while maintaining a short reading time. Our preliminary assessment suggests that INSIGHT3D provides added value to SM.

\section{Key points}

- INSIGHT3D depicts microcalcifications better than synthesized mammography while maintaining a low reading time.

- The diagnostic accuracy and inter-rater correlation were comparable between INSIGHT3D and synthesized mammography.

- INSIGHT3D may be a potential successor to synthesized mammography.

\section{Citation Format}

- Neubauer J, Neubauer C, Wicklein J et al. Multiple Angulated Mammography Reconstructions in Digital Breast Tomosynthesis for the Diagnosis of Microcalcifications - Added Value to Standard Stack Reconstructions and Synthesized Mammography. Fortschr Röntgenstr 2018; 190: 433-440

\section{Introduction}

Mammography has been shown to reduce breast cancer mortality [1]. However, the diagnostic accuracy of mammography for noncalcified masses can be limited due to superimposing breast parenchyma [2]. Digital Breast-Tomosynthesis (DBT) with multiple angulated projections and reconstructions can solve this issue to some extent and has been proven to outperform digital mammography in terms of lower recall rates and higher tumor detection rates $[3,4]$.

DBT, however, has a 1.5- to 2-fold higher radiation dose than Full Field Digital Mammography (FFDM) and in combination with FFDM will result in even higher radiation exposure to the patient [5]. Therefore, manufacturers established Synthesized Mammography (SM), which is reconstructed from tomosynthetic data. SM may replace FFDM while still enabling intuitive comparison to previous FFDM and evaluation of symmetry [6]. Although some studies show equal performance between SM and FFDM, other data suggest that SM might not be able to fully replace FFDM, especially regarding the evaluation of microcalcifications [7, 8]. Further development in the field of SM, therefore, seems to be mandatory.

Hence, we tested a new reconstruction technique with multiple angulated mammography reconstructions in digital breast tomosynthesis (INSIGHT3D ${ }^{1}$ ). INSIGHT3D reconstructions are similar to standard synthesized mammograms except that the

1 INSIGHT3D might not be commercially available in all countries. Its future availability cannot be ensured. views are reconstructed in multiple angulations. According to the projection images performed in DBT, these angulated views are reconstructed in increments of 2 degrees ranging from - 16 degrees to +16 degrees. In order to additionally strengthen the detection and assessment of microcalcifications, sub-pixel data of the microcalcifications are incorporated into these images. Due to the rotating focal plane of the INSIGHT3D images around the examination object, the reader is able to perceive a spatial three-dimensional conception of the configuration and distribution of microcalcifications. Since all projection data are employed in the reconstruction process, INSIGHT3D images do not suffer from high noise like the measured raw projections. Thus, our hypothesis is that INSIGHT3D outperforms conventional SM regarding the depiction of microcalcifications and performs equal to standard stack reconstructions in digital breast tomosynthesis. We compared ratings regarding the depiction of microcalcifications, diagnostic accuracy and inter-rater correlation between the tested modes of reconstruction.

\section{Materials and methods}

Our institutional Ethics Committee approved this retrospective, multicase, multireader observer performance study and informed consent was waived.

\section{Participants}

Patients were identified through our electronic health record system. We included two groups of patients for this study. Potentially 
eligible participants were patients who had undergone digital breast tomosynthesis between January and April 2017 at our institution for diagnostic reasons. We excluded all patients with incomplete imaging data and inadequate image quality. Group 1 consisted of all patients with microcalcifications that were investigated by histopathological evaluation. To simulate a realistic reading situation, we also included group 2, which consisted of the same number of patients without pathologic results (BI-RADS 1) and who had prior identically negative imaging over a period of at least 24 months. Patients for group 2 were selected in order of appearance with regard to their breast tissue density, with about $10 \%$ with fatty, $40 \%$ with scattered fibroglandular, $40 \%$ with heterogeneous and $10 \%$ with high density (BI-RADS A, B, C and D).

\section{Index tests}

Tomosynthesis was performed in the standard mediolateral oblique view with 25 projections over an angle of 50 degrees (MAMMOMAT Inspiration, Siemens Healthcare GmbH, Erlangen, Germany). Anode/filter W/Rh, automated exposure control and iterative reconstruction technique were used [9]. For each tomosynthesis data set a synthesized mammogram (SM/ INSIGHT2D) was reconstructed from the data. In addition to this synthetic mammogram, INSIGHT3D is a new technique that computes synthetic mammograms from different orientations within the tomosynthetic angular range. These multiple angulated mammograms were reconstructed in increments of 2 degrees over a range of - 16 degrees to +16 degrees. Depending on the details of the algorithm used, the INSIGHT3D mammogram in zero degree orientation may be equal to the synthetic mammogram INSIGHT2D, whereas the images from other angles provide views from different orientations. Interactive viewing by rotating the image data set within the available angular range allows rapid perception of spatial structures, particularly of microcalcification clusters.

The standard stack of slices was reconstructed with the iterative technique, utilizing the projection images and subpixel data of microcalcifications.

The images were pseudonymized with numbers and sent to a picture archiving and communication system (Syngo.via, Siemens Healthcare $\mathrm{GmbH}$, Erlangen, Germany). Readers were blinded to the patient data and presented with a written explanation for the evaluation containing extensive imaging examples for all semantic evaluation tasks.

Three radiologists trained in reading breast tomosynthesis with 6,7 and 25 years of clinical experience and a clinical caseload of at least 400 DBT in the last year independently evaluated the images at dedicated workstations under constant lighting conditions. SM, INSIGHT3D and stack reconstructions of each patient were displayed to the readers independently and in random order. Free windowing and zooming was permitted. Free scrolling was possible for the evaluation of INSIGHT3D and stack reconstructions.

The readers rated the depiction of microcalcifications semiquantitatively on a Likert scale $(0=$ no microcalcifications present, $1=$ very poor depiction of microcalcifications to $10=$ very good depiction of microcalcifications). Also, if microcalcifications were present, ratings regarding distribution (diffuse, regional, grouped, linear, segmental), morphology (typically benign, amorphous, coarse heterogeneous, fine pleomorphic, linear) and a final score (Breast Imaging Reporting and Data System [BI-RADS] 1, 2, $3,4,5)$ for the microcalcifications were forced. Reading time was measured for each mode.

\section{Reference test}

Histopathological evaluation

\section{Statistical analysis}

For statistical analysis only biopsy-proven cases were considered (group 1).

Ratings regarding the depiction of microcalcifications and reading time were compared between SM, INSIGHT3D and stack reconstructions with Friedman test and post hoc Nemenyi test. The mean ratings and reading time are stated.

The inter-rater agreement of the ratings regarding the distribution and morphology of microcalcifications was evaluated with Fleiss' kappa and confidence intervals (Cls) were computed applying bootstrapping (1000 replicates).

Considering categories 1 and 2 as negative and categories $3-5$ as positive, the BI-RADS ratings of all raters were pooled and the pooled sensitivity and specificity were calculated and compared using Cochrane's Q test and post hoc Wilcoxon sign test.

BI-RADS ratings of each reader were evaluated individually and compared using the receiver-operating characteristic (ROC) curves.

P-values $<0.05$ were assumed to denote statistical significance. False discovery rate was controlled according to Benjamini and Hochberg [10]. All Cls are stated at the $95 \%$ level. Statistical analysis was performed in $R$ ( $R$ version 3.2.4).

\section{Results}

We included a total of 82 patients, 41 patients in each group ( $\vee$ Fig. 1). The histopathological results for group 1 are stated in - Table 1. Imaging examples are presented in $\mathbf{F i g . 2 , 3}$. The mean ratings regarding the depiction of microcalcifications are stated in $>$ Table 2 and are significantly different between all reconstruction modes. The mean reading times are stated in $>$ Table 3 and are significantly different between the different reconstruction modes with the exception of the difference between SM and INSIGHT3D. The inter-rater agreement of the ratings regarding the distribution and morphology of microcalcifications is stated in - Table 4 (distribution) and > Table 5 (morphology) with overlapping $\mathrm{Cls}$ for each case. The pooled sensitivity and specificity for BI-RADS ratings are stated in $>$ Table 6 (sensitivity) and $\downarrow$ Table 7 (specificity) with no significant differences between reconstruction modes. Individual ROC curves and AUC values for all readers and reconstruction modes are stated in > Fig. 4 with overlapping $\mathrm{Cls}$ between all readers and all modalities. 


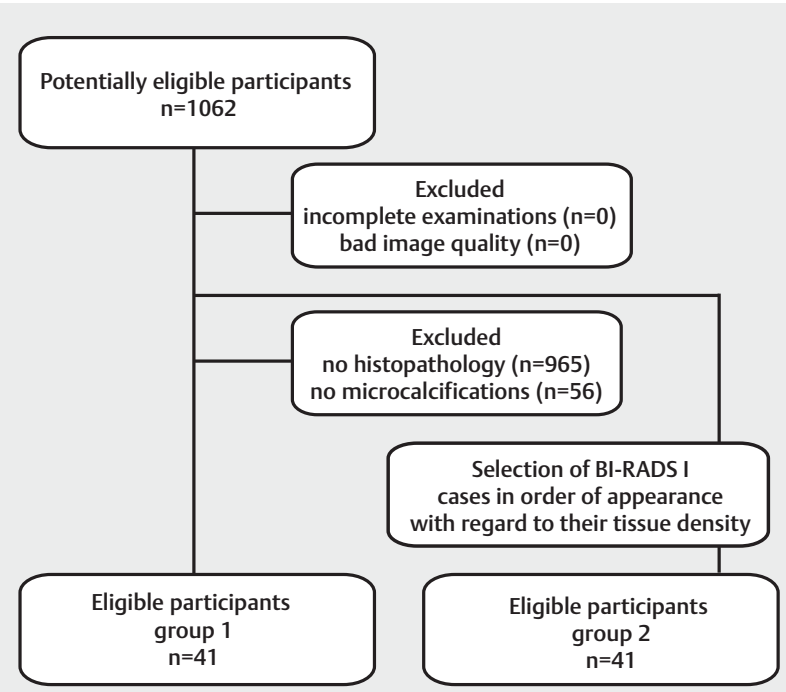

- Fig. 1 Flow diagram of participants.

- Abb. 1 Teilnehmerflussdiagramm.
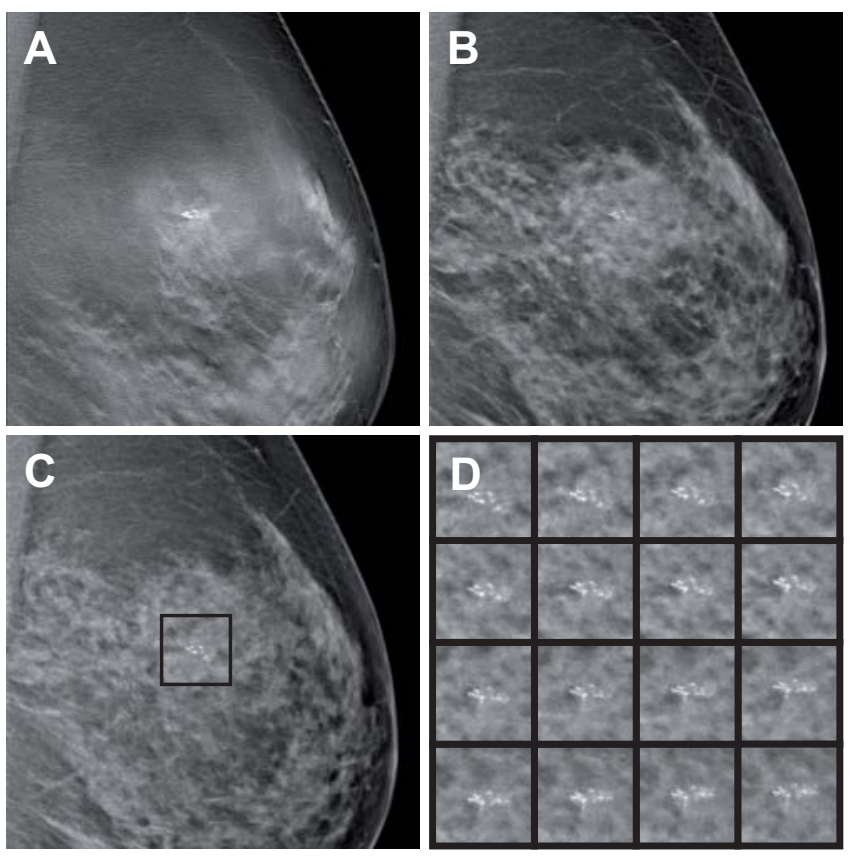

- Fig. 2 Imaging examples of grouped microcalcifications in the left upper outer quadrant in $\mathbf{A}$ standard stack reconstruction, B synthesized mammography/SM and C, D angulated mammography reconstructions/INSIGHT3D with $\mathbf{D}$ showing cropped enlargement in all angulations. With knowledge of all projections, there is a parenchymal asymmetry in the area of microcalcifications. Histopathological analysis revealed invasive carcinoma of no special type.

- Abb. 2 Bildbeispiele für gruppierte Mikroverkalkungen im linken oberen äußeren Quadranten in A Standard-Schicht-Rekonstruktion, B Synthetisierter Mammografie/SM und C, D angulierten Mammografie-Rekonstruktionen/INSIGHT3D mit D mit Ausschnittsvergrößerung in allen weiteren Angulationen. Unter Kenntnis aller Projektionen besteht im Areal der Mikroverkalkungen eine ParenchymAsymmetrie. Die Histopathologische Analyse ergab ein invasives Karzinom vom nicht speziellen Typ.
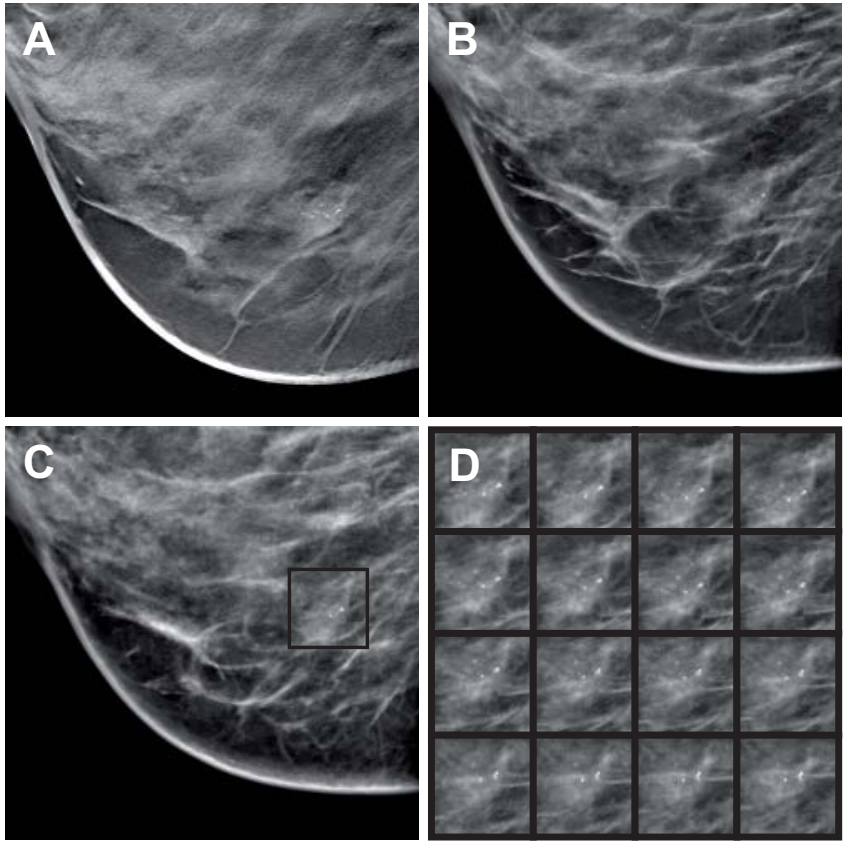

- Fig. 3 Imaging examples of grouped microcalcifications in the right lower inner quadrant in $\mathbf{A}$ standard stack reconstruction, B synthesized mammography/SM and C, D angulated mammography reconstructions/INSIGHT3D with $\mathbf{D}$ showing cropped enlargement in all angulations. Histopathological analysis revealed papilloma.

- Abb. 3 Bildbeispiele für gruppierte Mikroverkalkungen im rechten unteren inneren Quadranten in A Standard-Schicht-Rekonstruktion, B Synthetisierter Mammografie/SM und C, D angulierten Mammografie-Rekonstruktionen/INSIGHT3D mit D mit Ausschnittsvergrößerung in allen weiteren Angulationen. Die Histopathologische Analyse ergab ein Papillom.

\section{Discussion}

In this initial study we show that angulated mammography reconstructions in digital breast tomosynthesis (INSIGHT3D) get higher ratings for the depiction of microcalcifications than synthesized mammography (SM) but lower ratings than standard stack reconstructions in digital breast tomosynthesis. However, the reading time is shorter for INSIGHT3D than for standard stack reconstructions. Diagnostic accuracy and inter-rater correlation, on the other hand, are comparable between all tested modes of reconstruction.

These results present INSIGHT3D as a promising technique for the evaluation of digital breast tomosynthesis data. While the advantages of SM, such as better and faster comparability to previous examinations and contralateral imaging [6], are preserved with INSIGHT3D, its superior depiction of microcalcifications shows added value to SM. In this context, however, it should be remembered that it is not yet clear whether SM can generally substitute FFDM for the depiction of microcalcifications [7, 11, 12].

Compared to previously published studies [13], our reading time in general was relatively short. From our point of view, the evaluation process was mainly accelerated due to the reader's focus on microcalcifications. Interestingly, a slight but not statistically significant shorter reading time was registered for 


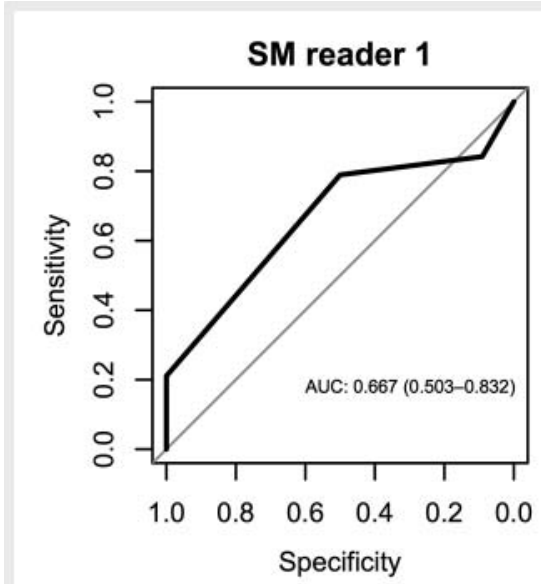

INSIGHT3D reader 1

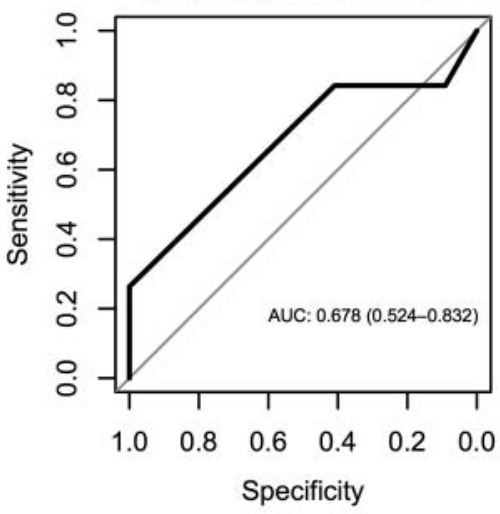

stack reader 1

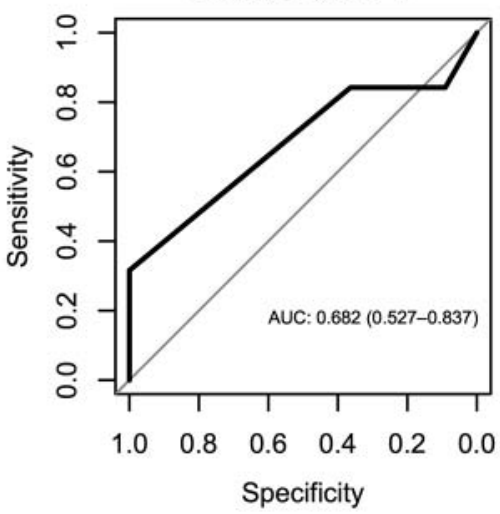

SM reader 2

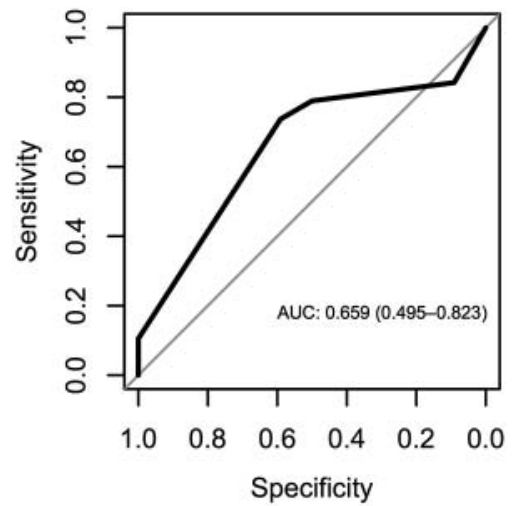

INSIGHT3D reader 2

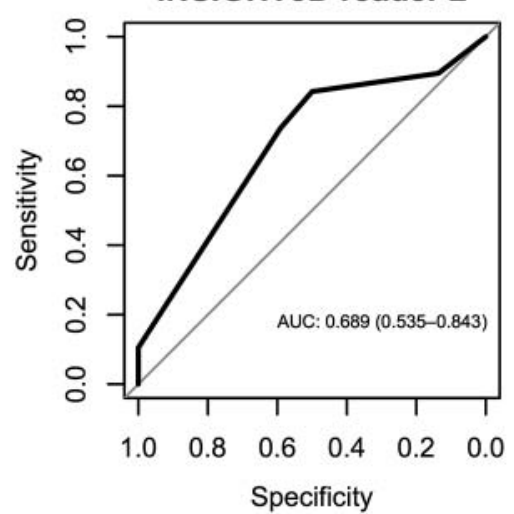

stack reader 2

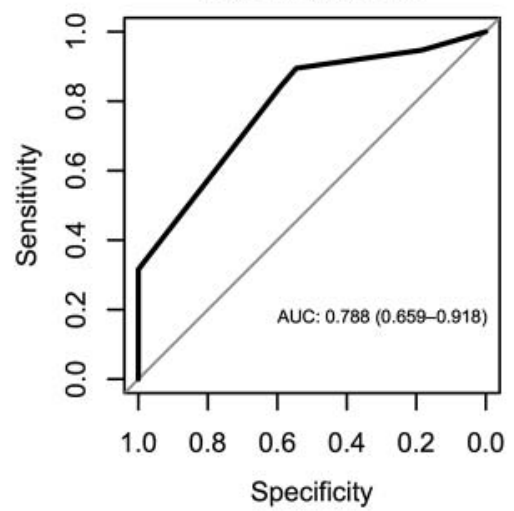

SM reader 3

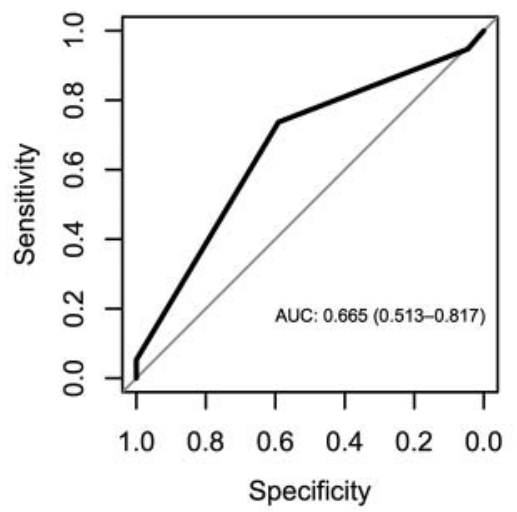

INSIGHT3D reader 3

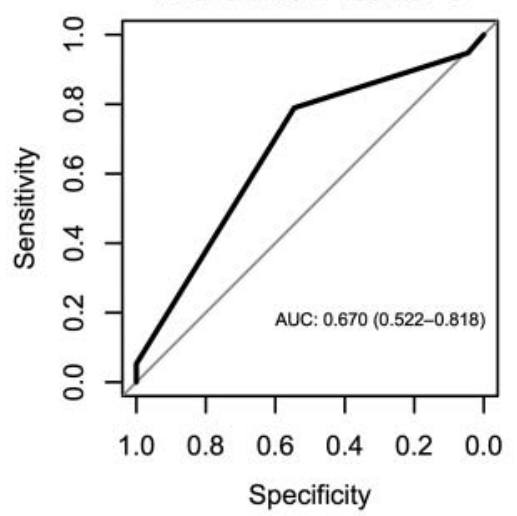

stack reader 3

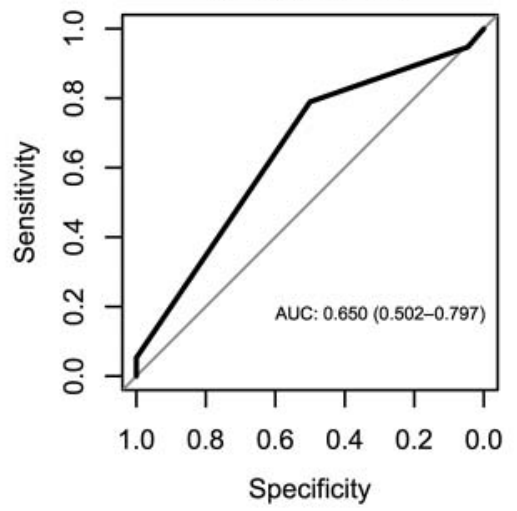

- Fig. 4 AUCs for all readers and all reconstruction modes (SM = Synthesized Mammography/ INSIGHT3D = multiple angulated mammography reconstructions in digital breast tomosynthesis).

- Abb. 4 AUCs für alle Leser und alle Rekonstruktionsmodi (SM = Synthetisierte Mammografie/ INSIGHT3 D = mehrfach angulierte Mammografierekonstruktionen in der digitalen Brusttomosynthese).

INSIGHT3D compared to SM. As an explanation, the better depiction of microcalcifications on INSIGHT3D may have supported and accelerated the decision-making process of the readers.

Reading of the standard stack reconstructions, however, still enabled the best evaluation of microcalcifications. Although it has a significantly shorter mean reading time, INSIGHT3D therefore will not be able to replace the time-consuming evaluation of standard stack reconstructions at this point. Further improvement of the reconstruction technique and reconstruction of INSIGHT3D over a greater angular range could possibly provide advantages that should be investigated in future studies.

The moderate inter-reader agreement for the morphology and distribution of microcalcifications seen in this study has previously been described for mammography [14] and tomosynthesis [3]. 
- Table 1 Histopathological results for all lesions with microcalcifications.

> Tab. 1 Histopathologische Ergebnisse für alle Läsionen mit Mikroverkalkungen.

\begin{tabular}{|c|c|c|c|}
\hline group & type & $\mathbf{n}$ & total(n) \\
\hline \multirow[t]{4}{*}{ malignant } & invasive carcinoma of no special type & 9 & \multirow[t]{4}{*}{15} \\
\hline & ductal carcinoma in situ & 4 & \\
\hline & mucinous carcinoma & 1 & \\
\hline & lobular carcinoma in situ & 1 & \\
\hline \multirow[t]{6}{*}{ benign } & fibrocystic changes & 15 & \multirow[t]{6}{*}{26} \\
\hline & fibroadenoma & 4 & \\
\hline & atypical lobular hyperplasia & 3 & \\
\hline & hyperplasia without atypia & 2 & \\
\hline & fat necrosis & 1 & \\
\hline & papilloma & 1 & \\
\hline
\end{tabular}

- Table 2 Mean ratings regarding the depiction of microcalcifications.

- Tab. 2 Durchschnittliche Bewertungen bezüglich der Darstellung von Mikroverkalkungen.

\begin{tabular}{|l|l|l|l|l|}
\hline & mean rating & friedman test & post hoc Nemenyi test compared to SM & post hoc Nemenyi test compared to INSIGHT3D \\
\hline SM & 5.7 & $<0.001$ & \\
\hline INSIGHT3D & 6.9 & & $<0.001$ & $<0.001$ \\
\hline Stack & 7.5 & $<0.001$ & \\
\hline
\end{tabular}

$1=$ very poor to 10 = very good $/$ SM = Synthesized Mammography $/$ INSIGHT3D = multiple angulated mammography reconstructions in digital breast tomosynthesis.

$1=$ sehr schlecht ... 10 = sehr gut $/$ SM = Synthetisierte Mammografie/ INSIGHT3D = mehrfach angulierte Mammografierekonstruktionen in der digitalen Brusttomosynthese.

- Table 3 Mean reading times.

- Tab.3 Durchschnittliche Lesezeiten.

\begin{tabular}{|l|l|l|l|l|}
\hline & $\begin{array}{l}\text { mean reading } \\
\text { time (s) }\end{array}$ & friedman test & post hoc Nemenyi test compared to SM & post hoc Nemenyi test compared to INSIGHT3D \\
\hline SM & 12.7 & $<0.001$ & & \\
\hline INSIGHT3D & 11.7 & & $>0.99$ & $<0.001$ \\
\hline stack & 24 & $<0.001$ & \\
\hline
\end{tabular}

SM = Synthesized Mammography/ INSIGHT3D = multiple angulated mammography reconstructions in digital breast tomosynthesis.

SM = Synthetisierte Mammografie/ INSIGHT3D = mehrfach angulierte Mammografierekonstruktionen in der digitalen Brusttomosynthese. 
- Table 4 Inter-rater agreement of the ratings regarding the distribution of microcalcifications.

- Tab.4 Inter-rater-Übereinstimmung der Bewertungen zur Verteilung von Mikroverkalkungen.

\begin{tabular}{|l|l|l|l|}
\hline distribution & fleiss' kappa & lower CI & upper Cl \\
\hline SM & 0.32 & 0.22 & 0.43 \\
\hline INSIGHT3 D & 0.24 & 0.15 & 0.35 \\
\hline stack & 0.23 & 0.13 & 0.34 \\
\hline
\end{tabular}

SM = Synthesized Mammography/ INSIGHT3 D = multiple angulated mammography reconstructions in digital breast tomosynthesis .

SM = Synthetisierte Mammografie/ INSIGHT3 D = mehrfach angulierte Mammografierekonstruktionen in der digitalen Brusttomosynthese.

- Table 5 Inter-rater agreement of the ratings regarding the morphology of microcalcifications.

- Tab.5 Inter-rater-Übereinstimmung der Bewertungen zur Morphologie von Mikroverkalkungen.

\begin{tabular}{|l|l|l|l|}
\hline morphology & fleiss' kappa & lower Cl & upper Cl \\
\hline SM & 0.33 & 0.23 & 0.44 \\
\hline INSIGHT3 D & 0.31 & 0.22 & 0.40 \\
\hline stack & 0.25 & 0.17 & 0.34 \\
\hline
\end{tabular}

SM = Synthesized Mammography / INSIGHT3 D = multiple angulated mammography reconstructions in digital breast tomosynthesis.

SM = Synthetisierte Mammografie/ INSIGHT3 D = mehrfach angulierte Mammografierekonstruktionen in der digitalen Brusttomosynthese.

- Table 6 Pooled sensitivity.

- Tab. 6 Gepoolte Sensitivität.

\begin{tabular}{|l|l|l|l|l|l|l|}
\hline & sensitivity & lower Cl & upper CI & cochrane's Q & $\begin{array}{l}\text { post hoc Wilcoxon sign test } \\
\text { compared to SM }\end{array}$ \\
\hline SM & 0.77 & 0.66 & 0.88 & 0.039 & \\
\hline INSIGHT3 D & 0.82 & 0.73 & 0.92 & & 0.375 \\
\hline stack & 0.84 & 0.75 & 0.94 & & 0.375 & $>0.99$ \\
\hline
\end{tabular}

SM = Synthesized Mammography $/$ INSIGHT3 D = multiple angulated mammography reconstructions in digital breast tomosynthesis.

SM = Synthetisierte Mammografie/ INSIGHT3 D = mehrfach angulierte Mammografierekonstruktionen in der digitalen Brusttomosynthese.

We found that this also holds true for INSIGHT3D without significant differences with respect to SM or the standard stack reconstruction. Previous studies about SM described a worse depiction of the morphology of microcalcifications compared to FFDM [7, 12]. This comparison, however, was not part of this study and describing the morphology with either of these reconstruction techniques might not be comparable with FFDM.

The results of this study are of clinical relevance: Given the better detectability of microcalcifications with INSIGHT3D compared to SM, INSIGHT3D might replace SM and thereby facilitate comparisons to previous FFDM examinations without increasing the reading time. This may be particularly true for the case in which previous FFDM has been performed in slightly altered angulation, which can be compensated by INSIGHT3D through its multiple angulations. From our point of view, the detection of all microcalcifications distributed over the whole breast is faster and safer with INSIGHT3D than with standard stack reconstructions. This may be related to the fact that microcalcification clusters are shown as a whole on INSIGHT3D images (the reconstruction image comprises the whole breast), but are separated on thinner standard stack reconstructions. Consequently, with standard stack reconstructions small clusters of calcifications are more 
- Table 7 Pooled specificity.

- Tab. 7 Gepoolte Spezifität.

\begin{tabular}{|c|c|c|c|c|}
\hline & specificity & lower Cl & upper $\mathrm{Cl}$ & cochrane's Q \\
\hline SM & 0.53 & 0.41 & 0.65 & \multirow[t]{3}{*}{0.115} \\
\hline INSIGHT3 D & 0.48 & 0.36 & 0.61 & \\
\hline stack & 0.47 & 0.35 & 0.90 & \\
\hline
\end{tabular}

likely to be overlooked and the actual geometric distribution of calcifications might be more difficult to perceive.

This is a retrospective study that is concerned only with the evaluation of microcalcifications, and the results must not be applied to the analysis of breast masses and the screening situation. Our analysis of our initial experiences with this new reconstruction technique in digital breast tomosynthesis is based on a relatively low number of cases. Small differences in the measurements of diagnostic accuracy undertaken in this study might therefore stay undetected. Tomosynthesis is superior to FFDM in the diagnosis of mass lesions. However, tomosynthesis still does not achieve the image quality of FFDM in the depiction of microcalcifications, where FFDM is still considered the gold standard [7, 12].

A direct comparison of INSIGHT3D with FFDM will be necessary to clarify the ultimately decisive question as to whether tomosynthesis can replace FFDM. This, however, was not part of this study.

Altogether, we demonstrate that angulated mammography reconstructions in digital breast tomosynthesis (INSIGHT3D) depict microcalcifications better than synthesized mammography (SM) while maintaining a short reading time. Our preliminary assessment suggests that INSIGHT3D provides added value to SM. Regarding diagnostic accuracy, no significant differences were detected between INSIGHT3D, SM, and standard stack reconstructions. Further studies with a larger number of patients and readers are necessary to confirm these results, including comparison to FFDM to evaluate the meaning and accuracy of each reconstruction method when compared to FFDM.

\section{Conflict of Interest}

J. W. and T. M. are Siemens Healthcare GmbH staff members. All other authors declared that they have no conflict of interest.

\section{References}

[1] Berry DA, Cronin KA, Plevritis SK et al. Effect of Screening and Adjuvant Therapy on Mortality from Breast Cancer. N Engl J Med 2005; 353: $1784-1792$

[2] Kolb TM, Lichy J, Newhouse JH. Comparison of the performance of screening mammography, physical examination, and breast US and evaluation of factors that influence them: an analysis of 27825 patient evaluations. Radiology 2002; 225: 165-175

[3] Clauser P, Nagl G, Helbich TH et al. Diagnostic performance of digital breast tomosynthesis with a wide scan angle compared to full-field digital mammography for the detection and characterization of microcalcifications. Eur J Radiol 2016; 85: 2161-2168

[4] Lang K, Andersson I, Rosso A et al. Performance of one-view breast tomosynthesis as a stand-alone breast cancer screening modality: results from the Malmö Breast Tomosynthesis Screening Trial, a population-based study. Eur Radiol 2016; 26: 184-190

[5] Kang H], Chang JM, Lee J et al. Replacing single-view mediolateral oblique (MLO) digital mammography (DM) with synthesized mammography (SM) with digital breast tomosynthesis (DBT) images: Comparison of the diagnostic performance and radiation dose with two-view DM with or without MLO-DBT. Eur J Radiol 2016; 85: 2042-2048

[6] Zuckerman SP, Maidment ADA, Weinstein SP et al. Imaging With Synthesized 2D Mammography: Differences, Advantages, and Pitfalls Compared With Digital Mammography. Am J Roentgenol. Am J Roentgenol 2017; 209: 222-229

[7] Peters S, Hellmich M, Stork A et al. Comparison of the Detection Rate of Simulated Microcalcifications in Full-Field Digital Mammography, Digital Breast Tomosynthesis, and Synthetically Reconstructed 2-Dimensional Images Performed With 2 Different Digital X-ray Mammography Systems. Invest Radiol 2017; 52: 206-215

[8] Gur D, Zuley ML, Anello Ml et al. Dose reduction in digital breast tomosynthesis (DBT) screening using synthetically reconstructed projection images: an observer performance study. Acad Radiol 2012; 19: 166-171

[9] Abdurahman S, Dennerlein F, Jerebko A et al. Optimizing high resolution reconstruction in digital breast tomosynthesis using filtered back projection. In: Lect. Notes Comput. Sci. (Including Subser. Lect. Notes Artif. Intell. Lect. Notes Bioinformatics). Springer International Publishing Switzerland 2014: 520-527

[10] Benjamini Y, Hochberg Y. Controlling the false discovery rate: a practical and powerful approach to multiple testing. J R Stat Soc B 1995; 57: 289300

[11] Choi JS, Han BK, Ko EY et al. Comparison between two-dimensional synthetic mammography reconstructed from digital breast tomosynthesis and full-field digital mammography for the detection of $\mathrm{T} 1$ breast cancer. Eur Radiol 2016; 26: 2538-2546

[12] Nelson JS, Wells JR, Baker JA et al. How does c-view image quality compare with conventional 2D FFDM? Med Phys 2016; 43: 2538

[13] Bernardi D, Ciatto S, Pellegrini M et al. Application of breast tomosynthesis in screening: incremental effect on mammography acquisition and reading time. $\mathrm{Br}$ J Radiol 2012; 85: e1174-e1178

[14] Berg WA, Campassi C, Langenberg P et al. Breast Imaging Reporting and Data System. Am J Roentgenol 2000; 174: 1769-1777 